\title{
Structural and spectroscopic characterization of $\mathrm{Ce}_{0.4} \mathrm{Zr}_{0.6} \mathrm{O}_{2}$ crystalline rods grown by the Laser Floating Zone method
}

\author{
M. L. SANJUÁN'1, P. B. OLIETE', A. VÁREZ², J. SANZ ${ }^{3}$
}

${ }^{1}$ Instituto de Ciencia de Materiales de Aragón, Universidad de Zaragoza-CSIC, Facultad de Ciencias, Universidad de Zaragoza, 50009 Zaragoza, ${ }^{2}$ Dpto. de Materiales, Universidad Carlos III de Madrid, Avda. Universidad 30, 28911 Leganés, Spain

${ }^{3}$ Instituto de Ciencia de Materiales (CSIC), Cantoblanco, 28049 Madrid, Spain

\begin{abstract}
A structural and spectroscopic characterization of crystalline rods of $\mathrm{Ce}_{04} \mathrm{Zr}_{06} \mathrm{O}_{2}$ grown by the laser floating zone (LFZ) method is presented. A precursor rod of $\mathrm{Ce}_{0.4} \mathrm{Zr}_{0.6} \mathrm{O}_{2}$ composition was sintered at $1500^{\circ} \mathrm{C}$ in air atmosphere and then processed by the LFZ technique with a $\mathrm{CO}_{2}$ laser. The processed material was characterized by XRD, SEM and Raman spectroscopy. In the as-grown, dark-color processed rod, the Raman spectrum evolves radially from a t'-like one, corresponding to $\mathrm{Ce}_{0.37} \mathrm{Zr}_{0.63} \mathrm{O}_{2}$ composition, at the edge of the rod, to a very broad and weak, cubic-like one, at the center. The degree of cerium reduction and oxygen non-stoichiometry were determined through measurements of the electronic Raman spectrum of Ce ${ }^{3+}$. A strong $\mathrm{Ce}^{3+}$ signal was found at the core of the rod, indicating strong reduction, whereas no $\mathrm{Ce}^{3+}$ signal was detected at the edge. To restore oxygen and $\mathrm{Ce}^{4+}$ content a section of the fiber was reoxidized at $620^{\circ} \mathrm{C}$ for $24 \mathrm{~h}$. A very homogeneous spectrum was found in the reoxidized sample, that was assigned to a $\mathrm{t}^{\prime}$-phase of composition $\mathrm{Ce}_{0.42} \mathrm{Zr}_{0.58} \mathrm{O}_{2}$.
\end{abstract}

Keywords: $\mathrm{ZrO}_{2}-\mathrm{CeO}_{2}$, phase diagram, Laser Floating Zone, Raman, $\mathrm{Ce}^{3+}$, Ce reduction.

Caracterización estructural y espectroscópica de fibras cristalinas de $\mathrm{Ce}_{0.4} \mathrm{Zr}_{0.6} \mathrm{O}_{2}$ crecidas mediante el método de fusión zonal asistida por láser

Presentamos una caracterización estructural y espectroscópica de fibras cristalinas de $\mathrm{Ce}_{0.4} \mathrm{Zr}_{0.6} \mathrm{O}_{2}$ crecidas mediante fusión zonal asistida por láser (LFZ). Una barra del material precursor, de composición $\mathrm{Ce}_{0.4} \mathrm{Zr}_{0.6} \mathrm{O}_{2}$, fue sinterizada a $1500{ }^{\circ} \mathrm{C}$ en atmósfera de aire y después procesada por LFZ con un láser de $\mathrm{CO}_{2}$. El material procesado fue caracterizado por difracción de rayos X, microscopía electrónica de barrido y espectroscopía Raman. En la fibra recién procesada, de color gris oscuro, el espectro Raman varía radialmente desde un espectro de tipo $\mathrm{t}^{\prime}$, correspondiente a una composición $\mathrm{Ce}_{0.37} \mathrm{Zr}_{0.63} \mathrm{O}_{2^{\prime}}$ en el borde de la fibra, hasta un espectro muy ensanchado y débil, de aspecto cúbico, en el centro. El grado de reducción del cerio y la no estequiometría del oxígeno se determinaron a través de las medidas del Raman electrónico del Ce ${ }^{3+}$. La señal de Ce $e^{3+}$ era muy intensa en el centro de la fibra, lo que indica una fuerte reducción, mientras que no se detectó en el borde. Para restablecer el contenido de oxígeno y de $\mathrm{Ce}^{4+}$ una parte de la fibra fue reoxidada a $620^{\circ} \mathrm{C}$ durante $24 \mathrm{~h}$. El espectro de la muestra reoxidada, de color amarillo pálido y muy homogénea, fue asignado a una fase $\mathrm{t}^{\prime}$ de composición $\mathrm{Ce}_{0.42} \mathrm{Zr}_{0.58} \mathrm{O}_{2}$.

Palabras clave: $\mathrm{ZrO}_{2}-\mathrm{CeO}_{2^{\prime}}$ diagrama de fases, fusión zonal por láser, Raman, $\mathrm{Ce}^{3+}$, reducción del Ce.

\section{INTRODUCTION}

In the past few years, intense research has been focused on the search of electrolytes for solid oxide fuel cells (SOFC) working at temperatures lower than those based on the $\mathrm{ZrO}_{2}-\mathrm{xY}_{2} \mathrm{O}_{3}$ system. Oxides derived from $\mathrm{CeO}_{2^{\prime}}$ such as $\mathrm{Ce}_{0.9} \mathrm{Gd}_{0.1} \mathrm{O}_{1.95^{\prime}}(1)$ are proposed as possible candidates. However, and depending on the temperature, $\mathrm{P}_{\mathrm{O}}$ and dopant concentration, the use of materials based on Ce oxides may be hampered by the tendence of this element to reduce itself from $\mathrm{Ce}^{4+}$ to $\mathrm{Ce}^{3+}$, which results in electronic conductivity.(2),(3)

This behavior, on the contrary, may be a possitive result for the use of Ce-based materials as anode components in intermediate-temperature-SOFC, where the catalytic activity of $\mathrm{CeO}_{2}$ may favor the direct oxidation of methane to $\mathrm{CO}_{2}+\mathrm{H}_{2} \mathrm{O}$.
(4) Finally, it is known that the addition of $\mathrm{ZrO}_{2}$ enhances the ability of $\mathrm{CeO}_{2}$ to store oxygen.(5) In fact, compounds of the system $\mathrm{Ce}_{1-x} \mathrm{Zr}_{x} \mathrm{O}_{2}$ have been proposed as "oxygen storage devices", taking advantage in that case of the simultaneous and reversible occurrence of oxygen loss (or retrapping) and Cerium reduction (or oxidation).(6)

We present in this work the fabrication and structural and spectroscopic characterization of crystalline rods of $\mathrm{Ce}_{0.4} \mathrm{Zr}_{0.6} \mathrm{O}_{2}$ composition. The purpose of our work is to produce single crystals by the laser floating zone (LFZ) technique and to analyse the resulting products in relation with the $\mathrm{CeO}_{2}-$ $\mathrm{ZrO}_{2}$ phase diagram. Emphasis is made in the spectroscopic characterization of the reduced phases present in the as-grown 
processed rod, since, to our knowledge, phases from the melt have not been previously studied.

Among the different solidification procedures to grow ceramic oxides from the melt, the techniques based on floating zone appear as excellent methods as no crucible is needed, allowing the growth of high purity crystals in rod form and with uniform diameter. Moreover, the thermal gradients at the liquid/solid interface are very large and, consequently, high growth rates can be used.

There are basically three variables to take into account in the $\mathrm{Ce}_{\mathrm{x}} \mathrm{Zr}_{1-\mathrm{x}} \mathrm{O}_{2}$ system: i) composition (that is, proportion of $\mathrm{Ce}^{4+}$ to $\left.\mathrm{Zr}^{4+}\right)$, ii) cationic order, according to which the structure may evolve from a fluorite-like one, when cation disorder is high, to pyrochlore-like phases, when Ce and $\mathrm{Zr}$ occupy different crystallographic sites, and iii) $\mathrm{Ce}^{4+}$ to $\mathrm{Ce}^{3+}$ reduction, that is accompanied by stoichiometry defects through the formation of oxygen vacancies.

According to the $\mathrm{CeO}_{2}-\mathrm{ZrO}_{2}$ phase diagram,(7) there are no stable solid solutions at room temperature (RT) of intermediate compositions and the $\mathrm{Ce}_{\mathrm{x}} \mathrm{Zr}_{1-\mathrm{x}} \mathrm{O}_{2}$ systems decompose into two extreme phases: a Zr-rich one, with monoclinic structure and very low Ce content, and a cubic fluorite phase with Ce content above $90 \%$. However, metastable phases of intermediate compositions (between $\approx 16$ and $80 \%$ Ce content) can be obtained by quenching from temperatures above $1600{ }^{\circ} \mathrm{C}$ and applying a subsequent reoxidizing treatment. (8),(9) For compositions below $65 \%$ the metastable $t^{\prime}$-phase is formed, with the same $\mathrm{P}_{2} / \mathrm{nmc}$ space group as tetragonal zirconia $\left(\mathrm{t}-\mathrm{ZrO}_{2}\right)$, and $\mathrm{c}>\mathrm{a}$. On the other hand, the pseudocubic $\mathrm{t}^{\prime \prime}$-phase found for Ce content between 65 and $80 \%$ is also tetragonal, with the same space group as $t^{\prime}$ phase, but has $\mathrm{c}=\mathrm{a}$. In both $\mathrm{t}^{\prime}$ and $\mathrm{t}^{\prime \prime}$ phases cations are distributed randomly. These limits are only approximate, since they depend on the sintering temperatures and cooling rates.

For compositions around $50 \%$, ordering of $\mathrm{Ce}$ and $\mathrm{Zr}$ cations results in the formation of pyrochlore phases, both reduced and oxidized, that can be described in a general formulation as $\mathrm{Ce}_{2} \mathrm{Zr}_{2} \mathrm{O}_{7+\delta}$. These phases are denoted as $\kappa$ in Refs. (10) and (11). If no cation ordering exists but $\mathrm{Ce}$ is partially reduced oxygen vacancies will appear in a cubic or tetragonal $(\mathrm{Ce}, \mathrm{Zr}) \mathrm{O}_{2-\delta}$ phase.

The usefulness of Raman scattering in ceria-zirconia systems is based on its sensitivity to small oxygen displacements, at a difference with $x$-ray diffraction (XRD). This allows to distinguish among very close phases with almost identical XRD patterns, that differ only in small variations of oxygen atomic positions, as is the case of the cubic and $t^{\prime \prime}$ phases. Raman scattering is also essential in small size systems, in which the large width of the diffraction peaks may preclude the distinction between cubic and tetragonal phases.

\section{EXPERIMENTAL DETAILS}

\subsection{Precursor rod preparation}

The precursors used in the LFZ growth were obtained from a mixture of commercial powders of cubic $\mathrm{CeO}_{2}(99.9 \%$, Aldrich) and monoclinic $\mathrm{ZrO}_{2}$ (99.9\% Aldrich) containing 40

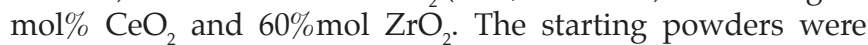
finely ground in acetone using an agate mortar. After drying, powders were cold isostatically pressed into latex cylinders (about $1 \mathrm{~cm}$ diameter and $1.5 \mathrm{~cm}$ height) at $200 \mathrm{MPa}$ and heated in a furnace during 24 hours at $1350{ }^{\circ} \mathrm{C}$. The obtained powders were hand-milled in an agate mortar. Cylinder shaped samples with a typical diameter of $3 \mathrm{~mm}$ and up to $100 \mathrm{~mm}$ in length were prepared by cold isostatic pressing for $2 \mathrm{~min}$ at $200 \mathrm{MPa}$, followed by sintering at $1500{ }^{\circ} \mathrm{C}$ for 12 hours to increase the density and provide handling strength. The heating and cooling rates used in the thermal treatments were $1^{\circ} \mathrm{C} \mathrm{min}^{-1}$.

\subsection{Crystal growth by the laser floating zone technique}

Rods of $\mathrm{Zr}_{0.6} \mathrm{Ce}_{0.4} \mathrm{O}_{2}$ were grown from the melt by the laser floating zone technique (LFZ) using a $\mathrm{CO}_{2}$ laser as described elsewhere.(12) Rods with $2 \mathrm{~mm}$ diameter were grown in air with downward pulling at $300 \mathrm{~mm} / \mathrm{h}$ and $500 \mathrm{~mm} / \mathrm{h}$ growth rates. The rotation speed of the precursor ceramic and the grown crystal was varied from 0 to $100 \mathrm{rpm}$.

The as-grown rods had a dark gray color due to oxygen deficiency. A grown rod was annealed in air for 24 hours at $620^{\circ} \mathrm{C}$ in order to restore the oxygen content and to obtain the stoichiometric zirconia solid solution $\mathrm{Ce}_{0.4} \mathrm{Zr}_{0.6} \mathrm{O}_{2}$. After annealing, the rod presented a pale yellow color.

For subsequent characterization and convenience in handling, the rods were mounted in a matrix of thermosetting polymer, that was cured under pressure and temperature simultaneously. Afterward, the mounted rod was cut to develop the inner part. Finally it was subjected to grinding and polishing with diamond paste.

\subsection{X-ray diffraction}

Powder X-Ray diffraction (XRD) experiments were carried out on a Philips X'Pert-MPD diffractometer $(\theta / 2 \theta$ BraggBrentano geometry) with a $\mathrm{Cu} \mathrm{K} \alpha$ radiation working at $40 \mathrm{kV}$ and $40 \mathrm{~mA}$. Patterns were recorded on a $2 \theta$ range of $20-120^{\circ}$, with the step-scanning mode $\left(0.02^{\circ}\right.$ step $) ; 8$ s of counting time; $1^{\circ}$ divergence slit; $1^{\circ}$ anti-scatter slit and $0.1 \mathrm{~mm}$ receiving slit.

Powders were dispersed in a single crystal Si stage oriented in a plane free of reflections. The mounted rod was located into a multipurpose stage that permits to perform XRD analysis of big three-dimensional samples.

The Rietveld refinement of XRD patterns was carried out by using the Fullprof program.(13) Zero corrections, scaling factors, unit cell parameters, peak shape parameters (including FWHM, asymmetry and pseudo-voigt profile functions) were determined.

\subsection{Scanning Electron Microscopy}

A Philips XL30 Scanning Electron Microscope equipped with a Backscattered (BSE) and a Energy Dispersive X-Ray (EDAX) detector was employed to study the microstructure and composition of the rods. The microscope operated almost always in backscattered mode between $15-20 \mathrm{kV}$, and all the EDAX analyses were registered at the same conditions of voltage $(20 \mathrm{kV})$, take-off angle and live time.

\subsection{Raman spectroscopy}

Raman measurements were performed in backscattering configuration at room temperature (RT) in a DILOR XY spectrometer with a liquid-nitrogen cooled Charge-Coupled Device (CCD) detector and excitation through the 50X objective lens of a microscope, using the $514.5 \mathrm{~nm}$ line of an $\mathrm{Ar}^{+}$laser. 
The Si mode at $520 \mathrm{~cm}^{-1}$ was used for frequency calibration. Lateral spatial resolution was of about $2 \mu \mathrm{m}$ and spectral linewidth $\approx 2 \mathrm{~cm}^{-1}$.

\section{EXPERIMENTAL RESULTS}

\subsection{XRD}

Figure 1 shows the XRD pattern of the precursor material sintered at $1500{ }^{\circ} \mathrm{C}$ for $12 \mathrm{~h}$. The pattern can be interpreted as the superposition of two diffractograms, corresponding to two tetragonal phases of the $\mathrm{Ce}_{\mathrm{x}} \mathrm{Zr}_{1-\mathrm{x}} \mathrm{O}_{2}$ system: a Ce-poor one, with $\mathrm{a}=3.6455(5)$ and $\mathrm{c}=5.2458(9)(\mathrm{c} / \mathrm{a}=1.017)$, and $\mathrm{a}$ Ce-rich one with $\mathrm{a}=3.7247(4)$ and $\mathrm{c}=5.3134(8)(\mathrm{c} / \mathrm{a}=1.008)$, that are assigned, according to the reported dependence of lattice parameters on composition for tetragonal $\mathrm{Ce}_{x} \mathrm{Zr}_{1-\mathrm{x}} \mathrm{O}_{2}$ systems, to a stable tetragonal phase close to $\mathrm{Ce}_{0.20} \mathrm{Zr}_{0.80} \mathrm{O}_{2^{\prime}}$ and to a metastable $\mathrm{t}^{\prime}$-phase of composition close to $\mathrm{Ce}_{0.55} \mathrm{Zr}_{0.45} \mathrm{O}_{2^{\prime}}$ respectively.(14)

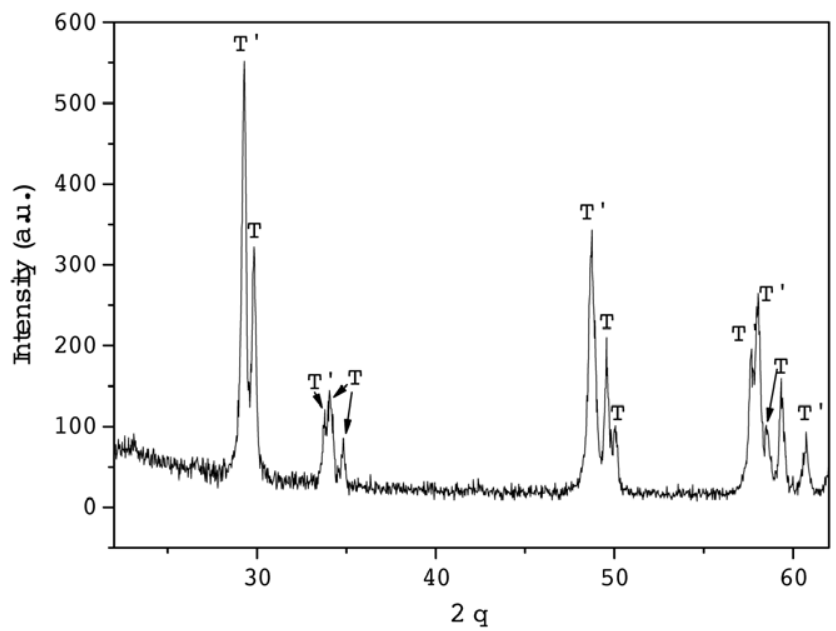

Fig. 1- XRD pattern of the $\mathrm{Ce}_{0.4} \mathrm{Zr}_{0.6} \mathrm{O}_{2}$ precursor sintered at $1500{ }^{\circ} \mathrm{C}$ during $12 \mathrm{~h}$. The most intense peaks of tetragonal $\mathrm{t}$ and $\mathrm{t}^{\prime}$ phases are indicated.

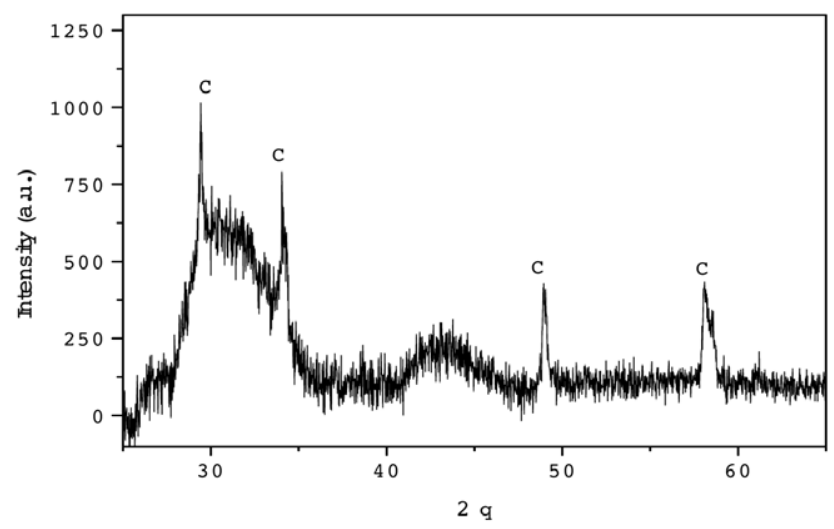

Fig. 2- XRD pattern of the as-grown LFZ processed rod. The broad bands centered at $2 \theta=20,32$ and $44^{\circ}$ assigned to the amorphous resin into which the rod was mounted.
For a better handling, the XRD experiments of the as-grown processed rod were performed on the sample mounted into the thermosetting resin. Due to the textured character of the rod, the relative intensities in such a diffractogram are expected to differ from those of a polycrystalline sample, but the peak positions can be used to get the lattice symmetry and parameters. The quality of the XRD pattern is not too high and it displays (Figure 2) very broad peaks centered at $2 \theta=$ 20,32 and $44^{\circ}$ assigned to the amorphous resin. The narrower peaks correspond to the crystalline rod and were assigned to a cubic fluorite phase with $\mathrm{a} \approx 5.268 \AA$, which corresponds, within error, to a Ce concentration very close to the nominal one $(x=0.4)$.

\subsection{Scanning Electron Microscopy}

Figure 3 shows a backscattered electron (BSE) micrograph of the precursor material sintered at $1500{ }^{\circ} \mathrm{C}$. Grains with different contrast can be distinguished, indicating the presence of two different phases. White contrast grains correspond to a Ce rich phase whereas black contrast areas are related with $\mathrm{Zr}$ rich compositions. EDS microanalysis showed that Ce: $\mathrm{Zr}$ ratio was 10.5:38.3 and 25.8:23.4 for the black and white contrast area respectively. These results were consistent with

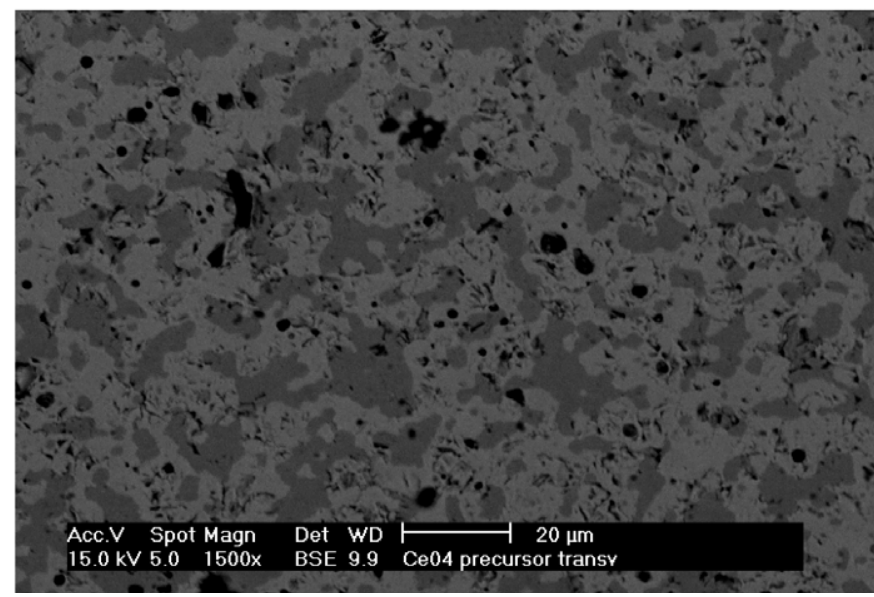

Fig. 3- Scanning Electron micrograph in Backscattered (BSE) mode of the precursor heated at $1500{ }^{\circ} \mathrm{C}$ during 12 hours, where two different areas with different contrast can be distinguished.

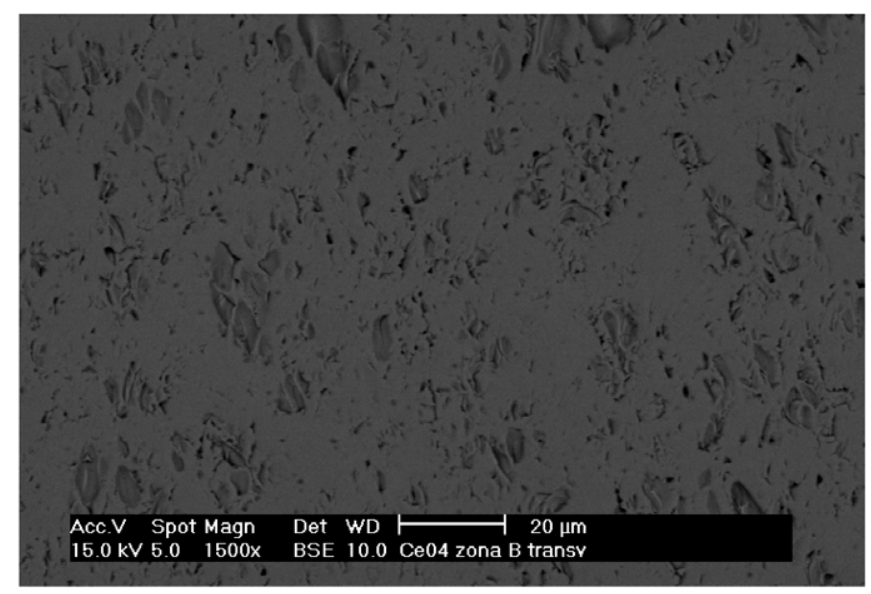

Fig. 4- Scanning Electron micrograph in Backscattered (BSE) mode of the grown fiber where grains with a single contrast are found. 
$\mathrm{Ce}_{0.22} \mathrm{Zr}_{0.78} \mathrm{O}_{2}$ and $\mathrm{Ce}_{0.52} \mathrm{Zr}_{0.48} \mathrm{O}_{2}$ compositions. Figure 4 displays the BSE micrograph of the LFZ grown rod. We can observe the presence of small erosions coming from the polishing of the samples. Except for erosion, only one contrast is revealed which should be consistent with a single phase, however when spot analysis was performed through the samples slight compositional fluctuations (between $\mathrm{Ce}=0.5$ and $\mathrm{Ce}=0.4$ ) were observed.

\subsection{Raman spectroscopy}

Raman spectra of the precursor material and of the LFZprocessed rod were recorded. These spectra were used for phase identification as well as for structural characterization, taking Yashima's Raman results (9) as a reference. According to Yashima's data, there are two regions of the spectrum that depend strongly on the $\mathrm{Ce} / \mathrm{Zr}$ composition. The first one is at $170-260 \mathrm{~cm}^{-1}$, where a mode varies from $\approx 260 \mathrm{~cm}^{-1}$ for tetragonal zirconia (data have to be taken either from high temperature spectra, or for low dimensionality systems, or for slightly doped $\mathrm{ZrO}_{2}$, to get the tetragonal phase) to less than $180 \mathrm{~cm}^{-1}$ as Ce content increases, up to the $\mathrm{t}^{\prime \prime}$ phase, where the mode disappears. The second interesting region is that above the strong peak at $455 \mathrm{~cm}^{-1}$, that is from 500 to $640 \mathrm{~cm}^{-1}$. In this region the shape of the spectrum is very sensitive to Ce content and also to oxygen stoichiometry, since it reflects mainly oxygen vibrations. We shall use both regions as criteria to assign the Ce content of the phases present in our samples.

\subsubsection{Spectroscopic characterization of the precursor}

For a full characterization of the precursor composition, Raman scattering of the rod sintered at $1500{ }^{\circ} \mathrm{C}$ for $12 \mathrm{~h}$ was performed. Spectra similar to that shown in Figure 5 were found throughout the sample, indicating a homogeneous composition. However, that spectrum cannot be assigned to a single phase of the $\mathrm{Ce}_{\mathrm{x}} \mathrm{Zr}_{1-\mathrm{x}} \mathrm{O}_{2}$ system: the presence of two separate bands in the $150-250 \mathrm{~cm}^{-1}$ region indicates that phase segregation has occurred. We assign the spectrum of Figure 5

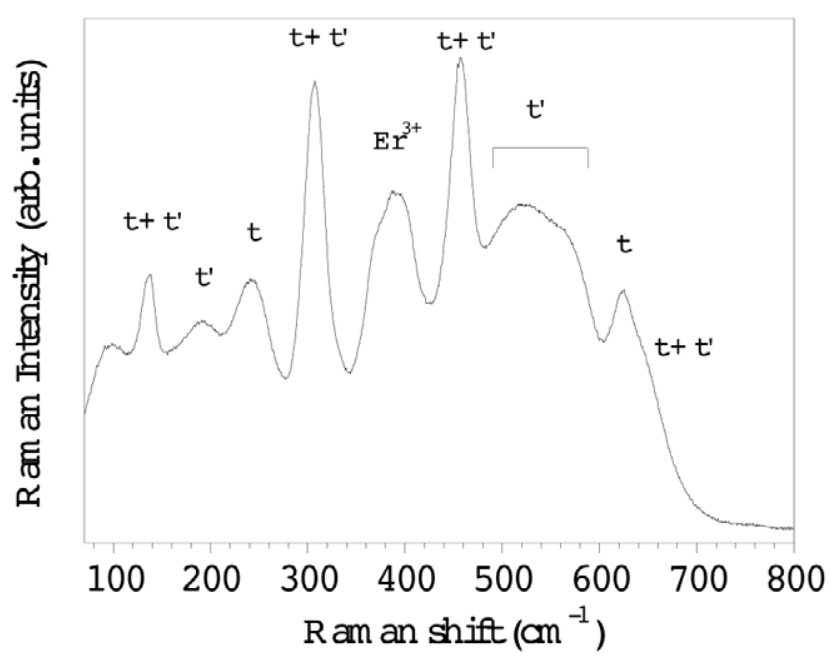

Fig. 5- Raman spectrum of the $\mathrm{Ce}_{0.4} \mathrm{Zr}_{0.6} \mathrm{O}_{2}$ precursor sintered in air at $1500{ }^{\circ} \mathrm{C}$ for $12 \mathrm{~h}$. The excitation wavelength is $514.5 \mathrm{~nm}$. The bands around $400 \mathrm{~cm}^{-1}$ arise from $\mathrm{Er}^{3+}$ luminescence. The spectrum is attributed to the superposition of two different spectra, arising from $t$ and $t^{\prime}$ like phases of Ce content around 17 and $52 \%$, respectively (see text). to a superposition of two tetragonal spectra of the $\mathrm{Ce}_{\mathrm{x}} \mathrm{Zr}_{1-\mathrm{x}} \mathrm{O}_{2}$ system, corresponding to compositions with $0.15 \leq \mathrm{x}^{\mathrm{x}} \leq 0.20$ (t-like) and $0.50 \leq \mathrm{x} \leq 0.55$ ( $\mathrm{t}^{\prime}$-like). Looking at the $\mathrm{ZrO}_{2}-\mathrm{CeO}_{2}$ phase diagram (7) we see that the composition close to $x=0.20$ is one of the stable phases expected at $1500{ }^{\circ} \mathrm{C}$, while the $t^{\prime}$-like phase with $x$ close to 0.50 is the metastable phase formed at that temperature. No cubic or $\mathrm{t}^{\prime \prime}$ spectra were found in these measurements. Bands between 360 and $420 \mathrm{~cm}^{-1}$ arise from hot luminescence of $\mathrm{Er}^{3+}$ impurities.(15)

\subsubsection{Spectroscopic characterization of the LFZ processed} rods

The processed rod was cut and polished along the longitudinal axis and in a transverse section. Spectra were taken at regular space increments in a radial sense from the edge to the middle of the rod. Representative spectra are shown in Figure 6. It can be seen that spectra evolve from an intense, $t^{\prime}$-like one, at the fiber edge, to a very broad and weak, cubic-like one at the middle. $t^{\prime}$-like spectra were seen up to a depth of about $50 \mu \mathrm{m}$. Between this $\mathrm{t}^{\prime}$-ring and the core giving a cubic-like spectrum an intermediate region, about $100 \mu \mathrm{m}$ thick, presented a broad but still $\mathrm{t}^{\prime}$-like spectrum. No significant dependence was observed on LFZ parameters such as growth rate or rotation, within the limits used in this work.

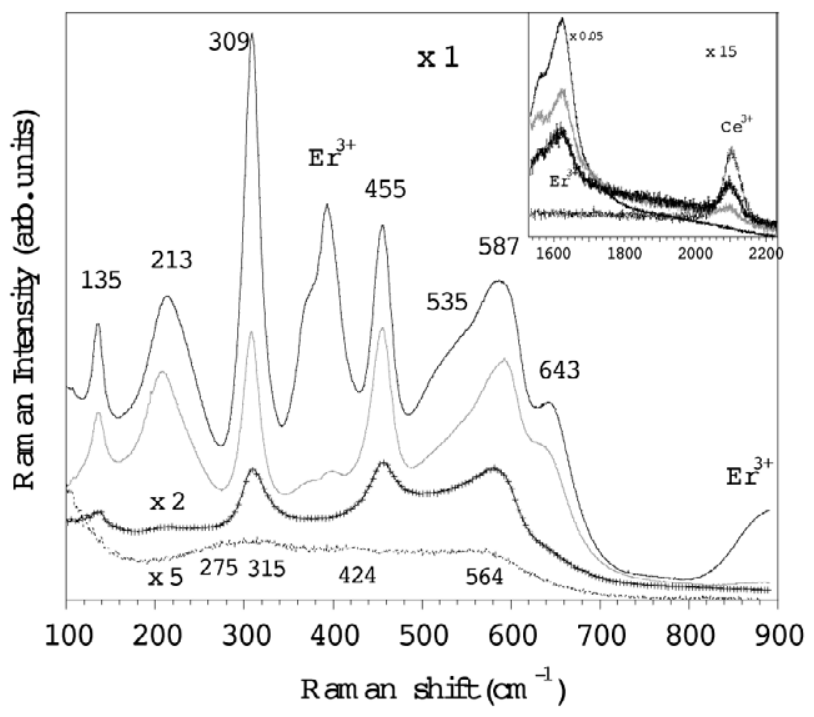

Fig. 6- Raman spectra of the as-grown LFZ processed rod of nominal composition $\mathrm{Ce}_{0.4} \mathrm{Zr}_{0.6} \mathrm{O}_{2}$. From the top to the bottom spectra were recorded onto different points of a longitudinal section shifted radially from the fiber edge (black solid line), toward the center (dashed line). The inset shows the spectra in the region of the electronic Raman spectrum of $\mathrm{Ce}^{3+}$, recorded at the same points giving the preceding spectra. The inset shows also other $\mathrm{Er}^{3+}$ luminescence bands.

The deep dark grey coloration of the sample indicated that a strong reduction had occurred during the LFZ growth. Therefore, $\mathrm{Ce}^{4+}$ to $\mathrm{Ce}^{3+}$ conversion and oxygen vacancy formation have to be considered as extra variables, besides the compositional and structural ones.

To quantify the degree of reduction we measured, in parallel with the low frequency region giving the bands of phononic origin, the electronic Raman spectrum of $\mathrm{Ce}^{3+}$ arising from the ${ }^{2} \mathrm{~F}_{5 / 2}$ to ${ }^{2} \mathrm{~F}_{7 / 2}$ transition, usually observed around 2100 
$\mathrm{cm}^{-1}$. These spectra are shown in the inset of Figure 6 and were recorded on the same points giving the spectra of the main part of the figure. A clear correlation can be established between both series of spectra:

i) At the edge, the $t^{\prime}$-like phonon spectrum is very intense. Strong $\mathrm{Er}^{3+}$ luminescence bands are observed in two different regions: around $400 \mathrm{~cm}^{-1}$ and around $1600 \mathrm{~cm}^{-1}$. No $\mathrm{Ce}^{3+}$ band is found.

ii) At the intermediate region, where the phonon spectrum appears as a broad, $t^{\prime}$-like one, the Er emission is strongly diminished and the $\mathrm{Ce}^{3+}$ electronic transition starts to be observed.

iii) Finally, at the middle of the fiber, the phonon spectrum is very weak, with broad bands indicating a highly disordered structure. No $\mathrm{Er}^{3+}$ luminescence is detected, and a strong $\mathrm{Ce}^{3+}$ band is found. We note that, compared to the phonon activity in t-zirconia or ceria materials, the electronic Raman spectrum is much less effective, thus the intensity of the $\mathrm{Ce}^{3+}$ bands presented in the figure can be considered as very high, which implies a strong reduction.

The inverse correlation betweeen $\mathrm{Ce}^{3+}$ electronic Raman spectrum and $\mathrm{Er}^{3+}$ luminescence is attributed to inhibition of the $\mathrm{Er}^{3+}$ luminescence due to absorption in the $\mathrm{Ce}^{3+}$ band (hv $\approx 20000 \mathrm{~cm}^{-1}$ ).

The presence of such a high concentration of $\mathrm{Ce}^{3+}$ ions (and, accordingly, of oxygen vacancies) is of importance for any structural consideration in zirconia-based systems, since $\mathrm{Ce}^{3+}$ may act as a dopant ion to stabilize high symmetry phases. Phase diagrams based exclusively on $\mathrm{ZrO}_{2}$ and $\mathrm{CeO}_{2}$ are no longer of use in the presence of $\mathrm{Ce}^{3+}$; the ternary $\mathrm{ZrO}_{2}-\mathrm{CeO}_{2}-$ $\mathrm{Ce}_{2} \mathrm{O}_{3}$ phase diagram should be used instead. Furthermore, effects due to Ce reduction and oxygen vacancies may mask other features, such as a possible loss of cation stoichiometry due to, for instance, Ce or Zr evaporation during the LFZ growth.

To avoid these problems, as well as to understand the nature of the cubic-like spectrum, we took a section of the processed fiber and reoxidized it at $620^{\circ} \mathrm{C}$ for $24 \mathrm{~h}$. The dark

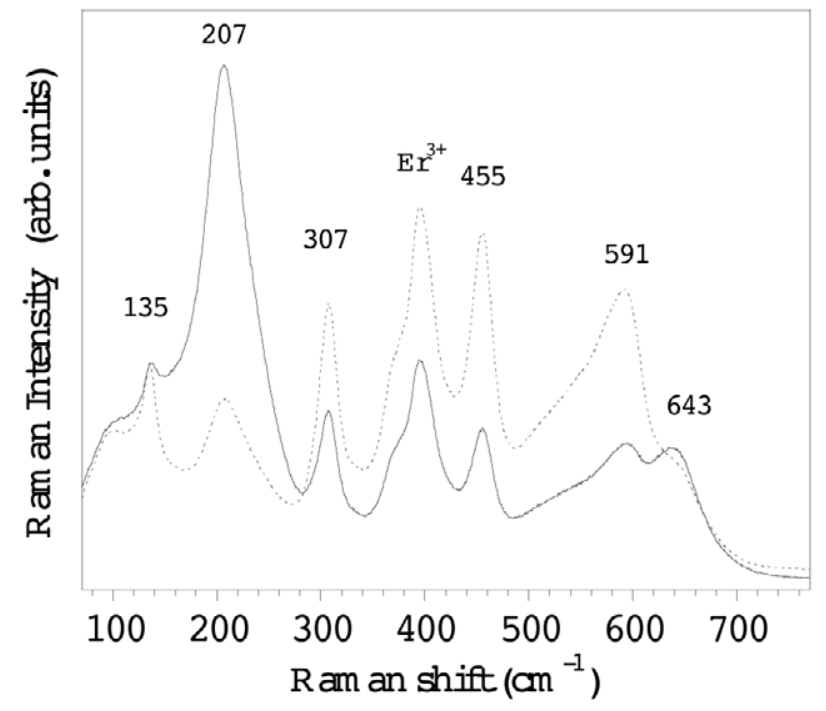

Fig. 7- Raman spectra performed onto a transverse section of the $\mathrm{Ce}_{0.4} \mathrm{Zr}_{0.6} \mathrm{O}_{2}$ fiber annealed in air at $620^{\circ} \mathrm{C}$ for $24 \mathrm{~h}$. Two different scattering configurations are shown, with the scattered electric field either parallel (continuous line) or perpendicular (dashed line) to the incident one. coloration disappeared after the oxidizing treatment and turned into a pale yellow color.

A single Raman spectrum was found in the annealed rod, in agreement with the detection of a single phase by SEM analysis. A representative Raman spectrum of the reoxidized sample is shown in Figure 7. It was homogeneously found throughout the sample and corresponds to a $t^{\prime}$-phase with a 0.40-0.45 cerium content, very close to the nominal one of the starting material. In all the spectra of the reoxidized sample (see Figure 7) the phonon peaks have narrowed, compared to the spectra of the as-grown rod, and the $\mathrm{Er}^{3+}$ luminescence can be seen. $\mathrm{No} \mathrm{Ce}^{3+}$ band was observed in the oxidized sample. As shown in Figure 7, clear polarization rules were observed, as corresponds to well-crystallized systems.

\section{FINAL DISCUSSION AND CONCLUSIONS}

We have grown textured crystalline rods of the $\mathrm{Ce}_{\mathrm{x}} \mathrm{Zr}_{1-\mathrm{x}} \mathrm{O}_{2}$ system with composition $\mathrm{x} \approx 0.4$ and metastable $\mathrm{t}^{\prime}$-phase structure. In relation with the phase diagram, the formation of the metastable $t^{\prime}$-phase is attributed to the fast cooling rates typical of LFZ crystal growth. Phase composition and structure were identified by means of XRD and Raman spectroscopy. Though strong reduction was seen to occur in the core of the as-grown LFZ-processed rod, homogenous structure and composition were found throught the sample after a reoxidizing treatment at $620{ }^{\circ} \mathrm{C}$. No significant dependence was observed on LFZ growth parameters, within the limits used in this work.

The following phase formation mechanism is proposed: With the LFZ technique, temperatures higher than $2500{ }^{\circ} \mathrm{C}$ are reached so that the rods are driven to the liquid field of the $\mathrm{CeO}_{2}-\mathrm{ZrO}_{2}$ phase diagram. These high temperatures favor $\mathrm{Ce}^{4+}$ to $\mathrm{Ce}^{3+}$ reduction, which gives the dark grey coloration. In these conditions and under fast cooling rates, a cubic-like phase is quenched, with composition close to the starting one $(x=0.4)$. We attribute this phase to the defective phase named $c^{\prime}$ by Yashima et al.(8),(16) However, reoxidation occurs at the surface of the rod during cooling, due to contact with air, up to a depth of several microns. That small region suffers the defective $c^{\prime}$ to non-defective $t^{\prime}$ phase transition also described by Yashima.(8),(16) The same kind of transformation occcurs for the rod annealed at $620{ }^{\circ} \mathrm{C}$ in air atmosphere: after annealing, the rod presents a pale yellow color and its Raman spectrum corresponds to an almost stoichiometric $t^{\prime}$ - phase with composition very close to $\mathrm{Ce}_{0.4} \mathrm{Zr}_{0.6} \mathrm{O}_{2}$.

\section{ACKNOWLEDGEMENTS}

Financial support from Spanish project MAT200403070-C05-03 is acknowledged.

\section{REFERENCES}

1. B. C. H. Steele and A. Heinzel, Materials for fuel-cell technologies, Nature 414, 345 (2001).

2. M. Mogensen, N. M. Sammes, G. A. Tompsett, Physical, chemical and electrochemical properties of pure and doped ceria, Solid State Ionics 129, 63-94 (2000).

3. B.C.H. Steele, Appraisal of $\mathrm{Ce}_{1-\mathrm{y}} \mathrm{Gd}_{\mathrm{y}} \mathrm{O}_{2-\mathrm{y} / 2}$ electrolytes for IT-SOFC operation at $500{ }^{\circ} \mathrm{C}$, Solid State Ionics $129,95-110$ (2000).

4. B.C.H. Steele, Running on natural gas, Nature 400, 619 (1999).

5. C. E. Hori, H. Permana, K.Y. Simon Ng, A. Brenner, K. More, K. M. Rahmoeller and D. Belton, Thermal stability of oxygen storage properties in a mixed $\mathrm{CeO}_{2}-\mathrm{ZrO}_{2}$ system, Appl. Catal. B 16, 105-117 (1998). 
6. P. Fornasiero, R. Di Monte, G.Ranga Rao, J. Kaspar, S. Meriani, A. Trovarelli and M. Graziani, Rh-loaded $\mathrm{CeO}_{2}-\mathrm{ZrO}_{2}$ solid-solutions as highly efficient oxygen exchangers: dependence of the reduction behavior and the oxygen storage capacity on the structural properties, Journal of Catalysis 151, 168-177 (1995); J. Kaspar, P. Fornasiero, M. Graziani, Use of $\mathrm{CeO}_{2}$-based oxides in the three-way catalysis, Catalysis Today 50, 285-298 (1999).

7. M. Yashima, T. Hirose, S. Katano, Y. Suzuki, M. Kakihana and M. Yoshimura, Structural changes of $\mathrm{ZrO}_{2}-\mathrm{CeO}_{2}$ solid solutions around the monoclinictetragonal phase boundary, Phys. Rev. B 51, 8018 (1995).

8. Masatomo Yashima, Kenji Morimoto, Nobuo Ishizawa and Masahiro Yoshimura, Diffusionless Tetragonal-Cubic Transformation Temperature in Zirconia-Ceria Solid Solutions, J. Am. Ceram. Soc. 76, 2865-68 (1993).

9. Masatomo Yashima, Haruo Arashi, Masato Kakihana and Masahiro Yoshimura, Raman Scattering Study of Cubic-Tetragonal Phase Transition in $\mathrm{Zr}$ Ce O Solid Solution, J. Am. Ceram. Soc. 77, 1067-71 (1994).

10. Takahisa Omata, Haruo Kishimoto, Shinya Otsuka-Yao-Matsuo, Norikazu Ohtori and Norimasa Umesaki, Vibrational Spectroscopic and X-Ray Diffraction Studies of Cerium Zirconium Oxides with Ce/Zr Composition Ratio=1 Prepared by Reduction and Successive Oxidation of $\mathrm{t}^{\prime}-\left(\mathrm{Ce}_{0.5} \mathrm{Zr}_{0.5}\right) \mathrm{O}_{2}$ Phase, J. Solid State Chem. 147, 573-583 (1999).
11. T. Montini, N. Hickey, P. Fornasiero, M. Graziani, M. A. Bañares, M. V Martínez-Huerta, I. Alessandri and L. E. Depero, Variations in the Extent of Pyrochlore-Type Cation Ordering in $\mathrm{Ce}_{2} \mathrm{Zr}_{2} \mathrm{O}_{8}$ : A t'- $\mathrm{\kappa}$ Pathway to LowTemperature Reduction, Chem. Mater. 17, 1157-1166 (2005).

12. G. F. de la Fuente, J. C. Díez, L. A. Angurel, J. I. Peña, A. Sotelo and R. Navarro, Wavelength dependence in laser floating-zone processing - a casestudy with Bi-Sr-Ca-Cu-O superconductors, Adv. Mater. 8, 853 (1995).

13. J. Rodríguez-Carvajal, Recent Advances in Magnetic-Structure Determination by Neutron Powder Diffraction, Physica B 192, 55-69 (1992). (Fullprof Program: Rietveld Pattern Matching Analysis of Powder Patterns, Grenoble, ILL, 1990).

14. A. Várez, E. García-González and J. Sanz, Cation miscibility in $\mathrm{CeO}_{2}-\mathrm{ZrO}_{2}$ oxides with fluorite structure. A combined TEM, SAED and XRD Rietveld analysis, J. Mater. Chem. 16, 4249-4256 (2006); A. Várez, E. García-González, J. Jolly and J. Sanz, J. Europ. Ceram. Soc. 2007, in press.

15. P. Fornasiero, A. Speghini, R. Di Monte, M. Bettinelli, Jan Kašpar, A. Bigotto, V. Sergo and M. Graziani, Laser-Excited Luminescence of Trivalent Lanthanide Impurities and Local Structure in $\mathrm{CeO}_{2}-\mathrm{ZrO}_{2}$ Mixed Oxides, Chem. Mater. 16, 1938-1944 (2004).

16. Masatomo Yashima, Kenji Morimoto, Nobuo Ishizawa and Masahiro Yoshimura, Zirconia-ceria solid solution synthesis and the temperaturetime-transformation diagram for the 1:1 composition, J. Am. Ceram. Soc. 76, 1745-50 (1993).

Recibido: 31.07 .07

Aceptado: 20.12 .07 